\title{
47 UNDERSTANDING USE OF CHILD RESTRAINTS IN AUSTRALIAN ABORIGINAL FAMILIES: A MIXED METHODS APPROACH
}

doi:10.1136/injuryprev-2012-040590d.47

${ }^{1} \mathrm{~K}$ Hunter, ${ }^{1} \mathrm{~L}$ Keay, ${ }^{2} \mathrm{~K}$ Clapham, ${ }^{1} \mathrm{M}$ Lyford, ${ }^{3} \mathrm{~J}$ Brown, ${ }^{3} \mathrm{~L}$ Bilston, ${ }^{4} \mathrm{~W}$ Lo, ${ }^{1} \mathrm{R}$ Ivers.

${ }^{1}$ The George Institute for Global Health, The University of Sydney, Australia; ${ }^{2}$ Australian Health Services Research Institute, The University of Wollongong, Australia;

${ }^{3}$ Neuroscience Research Australia, The University of New South Wales, Australia;

${ }^{4}$ School of Public Health, The University of New South Wales, Australia

Background Aboriginal children are over represented in car crash fatalities, however little is known about knowledge and attitudes towards use of child restraints in Aboriginal communities in Australia.

Aims/Objectives/Purpose To explore the knowledge, attitudes and factors that impede and facilitate the use of appropriate restraints in Aboriginal communities.

Methods A mixed method approach included a parent survey across three early learning centres where approximately a third of children are of Aboriginal descent on the Australian south-east coast, and six focus groups, comprising 38 parents recruited from the early learning centres and two urban Aboriginal Controlled Health services.

Results/0utcomes Survey data showed while the majority of families (90/97, 94\%) were aware of the new restraint legislation and 80 (83\%) correctly identified the restraint for their child's age as defined by the law, there were gaps in knowledge about transition ages, particularly for when to move their child to a booster seat (legislated age four or older). In the focus groups, parents expressed some confusion about the new legislation and when to progress a child from one restraint to the next. Both the cost of restraints and sharing rides with other families were identified as barriers. Parents said their child's safety was of paramount importance to them and that relatives and other community members influenced how their child travelled.

Significance/Contributions to the Field This study highlights the factors that should be addressed in programmes targeting restraint use in Aboriginal populations. 